\title{
Source-Induced Dissociation Vs Collision-Induced Dissociation Fragmentation Behavior of Four Antiviral Drugs in a Liquid Chromatography Ion-Trap Mass Spectrometry
}

\author{
A F M Motiur Rahman*, Mohamed W Attwa and Adnan A Kadi \\ Department of Pharmaceutical Chemistry, College of Pharmacy, King Saud University, P.O. Box 2457 Riyadh, 11451, Saudi \\ Arabia
}

*Corresponding author: A F M Motiur Rahman, Department of Pharmaceutical Chemistry, College of Pharmacy, King Saud University, P.O. Box 2457 Riyadh, 11451, Saudi Arabia

\section{ARTICLE INFO}

Received: 慧 September 09, 2021

Published: 㓞 September 20, 2021

Citation: A F M Motiur Rahman, Mohamed W Attwa and Adnan A Kadi. Source-Induced Dissociation Vs Collision-Induced Dissociation Fragmentation Behavior of Four Antiviral Drugs in a Liquid Chromatography Ion-Trap Mass Spectrometry. Biomed J Sci \& Tech Res 38(5)-2021. BJSTR. MS.ID.006218.

\begin{abstract}
Mass Spectrometry (MS) is an important tool for analyzing or detecting a wide range of natural and unnatural molecules. In this study, fragmentation pathways of four antiviral drugs (Acyclovir, Abacavir, Famciclovir and Penciclovir) were investigated using two possible fragmentation methods of Ion-Trap mass spectrometry (ITMS). Sourceinduced dissociation (SID) and collision-induced dissociation (CID) fragmentation in ESI Ion-Trap were compared to get the maximum benefit of the qualitative power of ITMS. Fragmentation pattern of these four antiviral drugs by direct injection using infusion pump were examined. Mass spectrometric parameters were optimized for each drug. Interpretation of the generated data were performed. More qualitative information was obtained using SID comparing to CID of ESI Ion-Trap for fragmentation of four antiviral drugs acyclovir, abacavir, famciclovir and penciclovir. This method can be used for the identification / detection of these antiviral drugs as well as other molecules in a mixture or in biological matrixes. This could be a new strategy to get more qualitative information for unknown related compounds using ITMS.
\end{abstract}

Keywords: ITMS; Source-Induced Dissociation; Collision-Induced Dissociation; Antiviral Drugs; Fragmentation Behavior

\section{Introduction}

Mass spectrometry (MS) is an important tool for analyzing or detecting a wide range of organic, inorganic, natural, unnatural molecules, especially drugs, proteins, peptides are of interests beside routine analysis [1]. MS measures the mass-to-charge ratios of ions of an ionized sample, which may be gas, liquid or solids. Mass-to-charge ratios may obtain for a charged molecule or charged fragments. MS has both quantitative and qualitative uses. Numerous ionization methods are used in MS experiments, such as chemical ionization (CI), matrix assisted laser desorption ionization (MALDI), electron impact (EI), atmospheric pressure chemical ionization (APCI), and electrospray ionization (ESI). ESIMS has been applied to the analysis of oligonucleotides [2, 3] drugs and drug metabolites [4] oligosaccharides [5, 6] environmental contaminants [7, 8] glycoproteins [9] and many other types of compounds [10-15]. In atmospheric pressure ion sources, e.g., ESI or APCI, dissociation of ions can occur inside the ionization source (source induced dissociation; SID) before reaching the mass analyzer. SID has been used by several research groups [16-22]. Usually, SID is used to analyze single mass, whereas CID is used to analyze fragmentation. Both SID and CID techniques having 
advantages and disadvantages [23, 24]. While CID technique is very much effective to analyze pure sample with much more information about structural data [25]. Acyclovir, [26, 27] abacavir, $[28,29]$ famciclovir [30-33] and penciclovir [10] are the known antiviral medication used to prevent viral diseases. All of these antiviral drugs having common purine moiety [34] (Figure 1) and 9-position of purine are substituted with deferent alkyl chains.
Mass spectrometric study of these structurally similar compounds may reveal lots of information for further analysis process during antiviral doses. As a medicinal chemist, it is our duty to develop drug molecules / administration procedures / toxicity evaluation process and / identification in a mixture or in biological matrixes. Therefore, there is always a room for extending such development using modern scientific methods such as mass spectrometry.

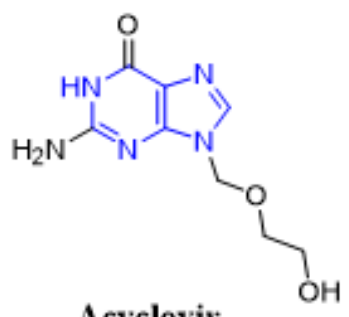

Acyclovir

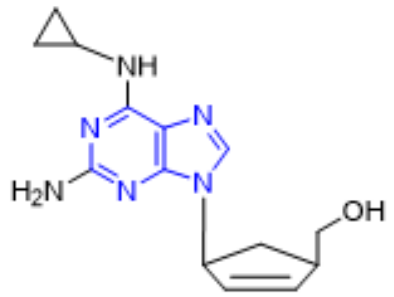

Abacavir<smiles>Nc1nc(=O)c2ncn(CCC(CO)CO)c2[nH]1</smiles>

Penciclovir

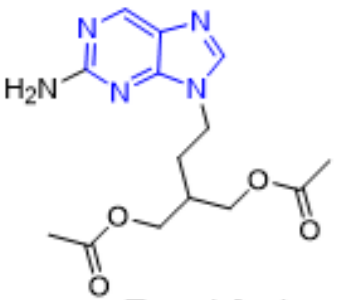

Famciclovir

Figure 1: Chemical structures of antiviral acyclovir, abacavir, penciclovir and famciclovir showing a common purine nucleus.

Here, analysis of four antiviral drugs acyclovir, abacavir, penciclovir and famciclovir serves to figure out how to extend the qualitative power of ITMS and to maximize the benefit from this mass analyzer. These four drugs also were selected as they contain a common purine nucleus in their chemical structures which might generates a common fragmentation pattern. Above mentioned four known antiviral drugs were studied for their fragmentation pathways and data of SID and CID of ESI IT were compared. The detail fragmentation pathways of all ions observed in the in-source fragmentation spectrum of compounds were elucidated by further dissociation of each of these fragment ions using $\mathrm{MS}^{2}, \mathrm{MS}^{3}$ and $\mathrm{MS}^{4}$ fragmentation stages.

\section{Experimental}

An Agilent 6320 Ion-Trap connected (LC-MS $\left.{ }^{\mathrm{n}}\right)$ mass spectrometer was used. Compounds were dissolved in DMSO and used as standard solution, then diluted with a mixture of HPLC grade water and acetonitrile (1:1). Fragmentation pattern of these four antiviral drugs by direct injection using infusion pump were performed. $10 \mu \mathrm{L}$ of each sample was injected with direct injection, flow rate was $0.4 \mathrm{ml} / \mathrm{min}$., run time was set to 5 minutes, drying gas was $\mathrm{N}_{2}$ (flow was $12 \mathrm{~L} / \mathrm{min}$ ), temperature was set to $350{ }^{\circ} \mathrm{C}$, nebulizer pressure was $50 \mathrm{psi}$, smart target was 10,000 , accumulation time $150 \mathrm{~ms}$, scan range was 20-400Da and Ion source was ESI, in positive mode with ultra-scan. There are several factors that can influence the fragmentation spectra, such as the collision energy, major precursor ion, electrospray mode (positive or negative) and capillary exit voltage. In IT, product ion scan was performed before the in-source fragmentation to determine each compound's related fragment ions, the capillary exit voltage was optimized to produce adequate in-source fragmentation. The data compared to multistage fragmentation using CID. We made all default parameters except capillary exit voltage which was $100 \mathrm{~V}$ for CID and $200 \mathrm{~V}$ for SID.

\section{Results and Discussion}

\section{CID MS $^{\mathrm{n}}$ Fragmentation Pattern of Abacavir}

Abacavir was set for an example of comparing two fragmentation techniques. As shown in (Figures 2 \& 3), full scan of abacavir gave $\mathrm{m} / \mathrm{z} 287$ (Figure 2A) and $\mathrm{MS}^{2}$ of abacavir gave three fragments at $\mathrm{m} / \mathrm{z} 257,191$ and 150 (Figure 2B). Among three fragments, $\mathrm{m} / \mathrm{z} 191$ was a prominent peak which was further bombarded $\left(\mathrm{MS}^{3}\right)$ and gave $\mathrm{m} / \mathrm{z}$ 174, 164, 150, 134, 109, 83 and 59 (Figure 2C). Consequently, high intense three ions m/z 174, 164 and 150 were further bombarded (MS ${ }^{4}$ ) in which, $\mathrm{m} / \mathrm{z} 174$ gave four ions at $\mathrm{m} / \mathrm{z}$ 159, 148, 132 and 157 (Figure 3A), m/z 164 gave two ions m/z 137 and 122 (Figure 3B), and m/z 150 gave a single ion at $\mathrm{m} / \mathrm{z} 132$ (Figure 3C).Based on (Figures 2\& 3), we have drawn Scheme 1 for the fragmentation pattern of abacavir in CID mode. As shown in scheme 1 , after four steps $\left(\mathrm{MS}^{4}\right)$ fragmentation, abacavir gave maximum fragments at $\mathrm{m} / \mathrm{z} 150,147,137,134,132,122$, and 57. SID pseudo-MS ${ }^{\mathrm{n}}$ fragmentation pattern of abacavir. As shown (Figure 4), pseudo MS ${ }^{2}$ of abacavir gave $\mathrm{m} / \mathrm{z} 287,191,174,164,150$ and 134 (Figure $4 \mathrm{~A}$ ), and pseudo $\mathrm{MS}^{3}$ of major two fragments, $\mathrm{m} / \mathrm{z}$ 191 and 174 was further bombarded $\left(\mathrm{MS}^{3}\right)$ and obtained m/z 191 gave $\mathrm{m} / \mathrm{z}$ 174, 164, 150, 136, 109 and 59 (Figure 4B) and m/z 174 gave $\mathrm{m} / \mathrm{z}$ 147, 134, 119, 106, 94 and 57 (Figure 4C), respectively. Pseudo $\mathrm{MS}^{4}$ of high intense m/z 174 gave m/z 164, 147, 134, 122, 93 and 57 (Figure 4D). 


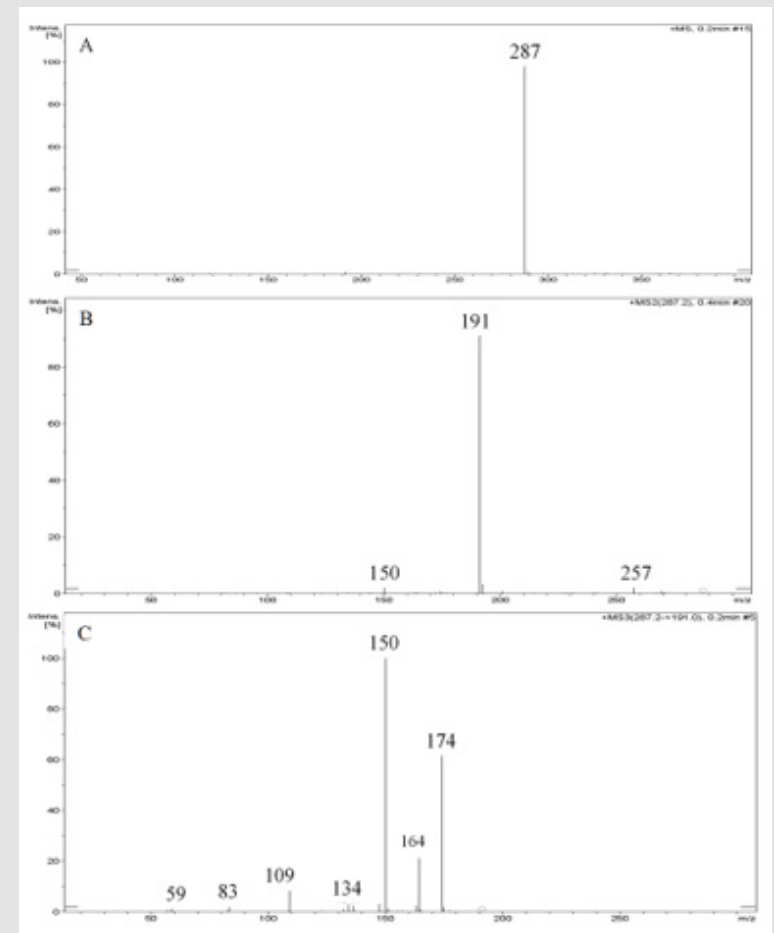

Figure 2: $\mathrm{CID} \mathrm{MS}^{\mathrm{n}}$ fragmentation pattern of abacavir:

A. MS scan for abacavir,

B. $\mathrm{MS}^{2}$ of 287 and

C. $\mathrm{MS}^{3}$ of 191.

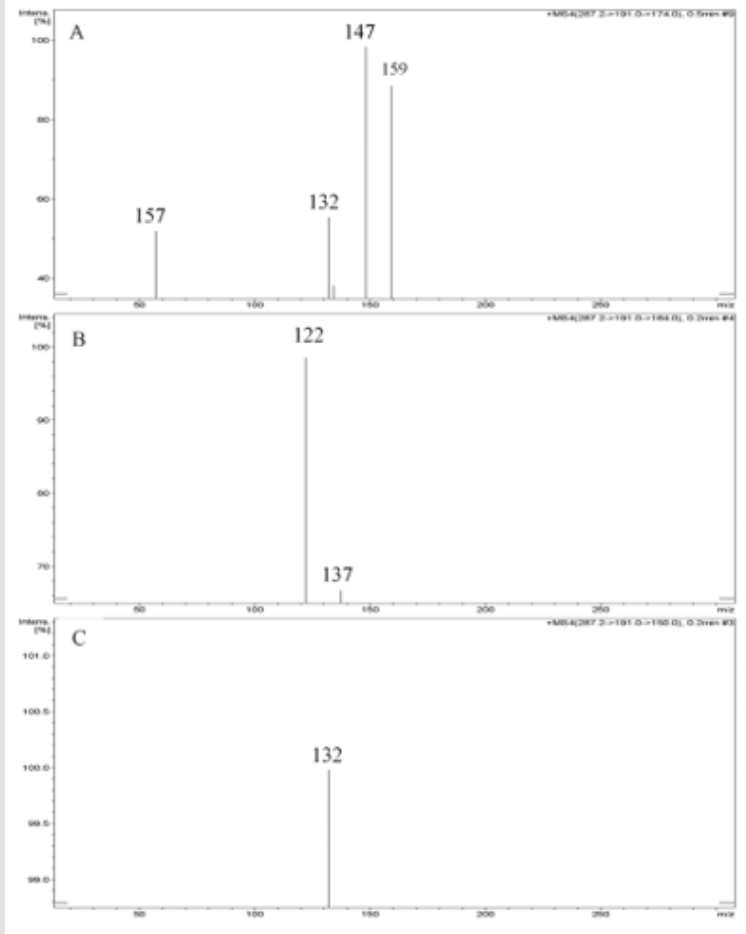

Figure 3: $\mathrm{CID} \mathrm{MS}^{4}$ fragmentation of three ions (174, 164 and 150):

A. MS ${ }^{4}$ scan of 174

B. MS ${ }^{4}$ scan of 164 and

C. $\mathrm{MS}^{4}$ scan of 150 


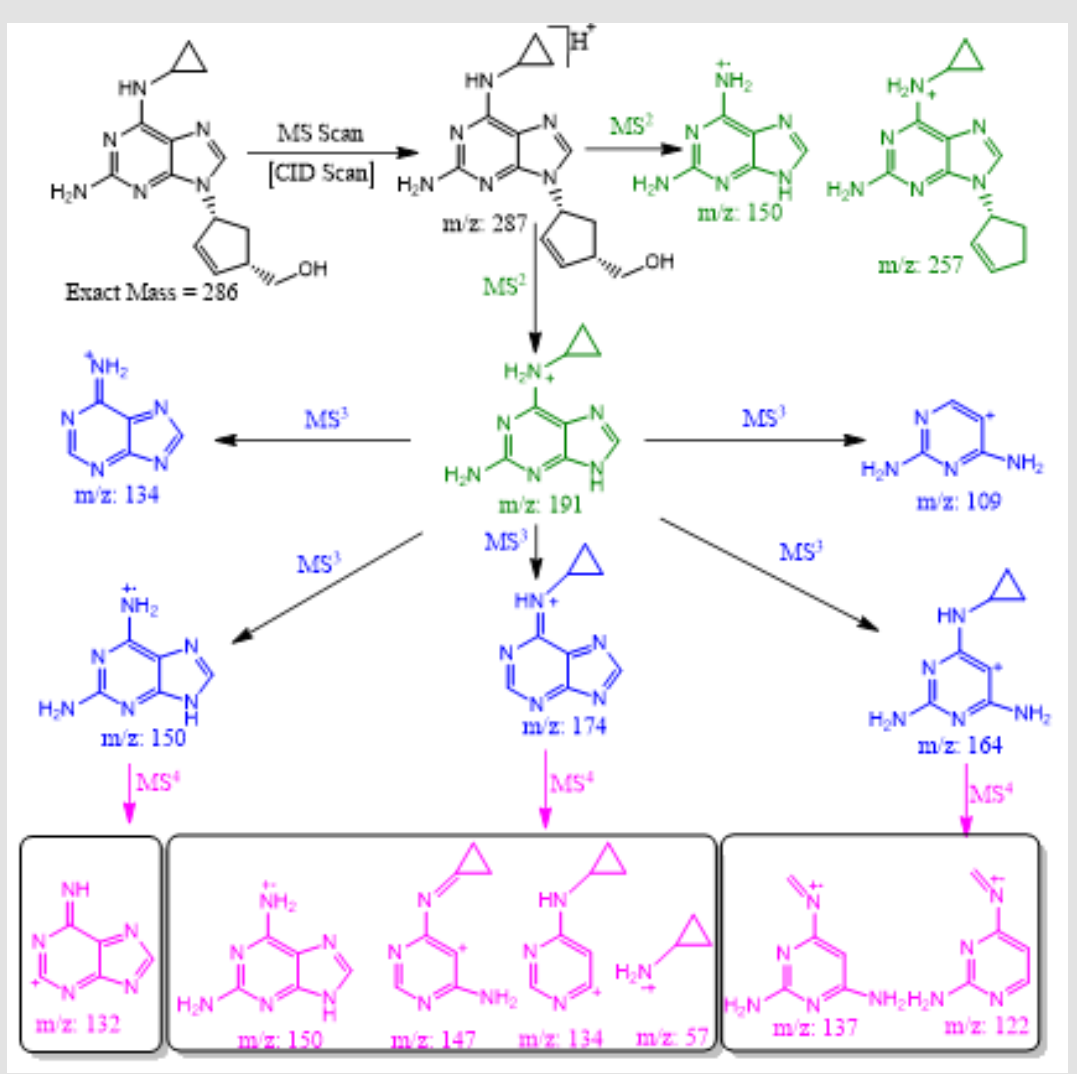

Scheme 1: CID MS ${ }^{n}$ fragmentation pattern of protonated abacavir.

Based on (Figure 4), we have drawn Scheme 2 for the fragmentation pattern of abacavir in SID mode. As shown in scheme 2, in two steps (pseudo MS ${ }^{3}$ ) fragmentation, abacavir gave maximum fragments at $\mathrm{m} / \mathrm{z} 174,150,147,134,132,109$ and 94 and pseudo MS4 of m/z 174 gave five fragments at m/z 164, 147, 134, 121 and 57. SID and CID of acyclovir, penciclovir and famciclovir. Other three antiviral drugs acyclovir, penciclovir and famciclovir mass spectrometric study in SID and CID results are summarized in Table 1 along with abacavir. As shown in Table 1 and depicted in Scheme 3 , SID scan of acyclovir gave m/z $226[\mathrm{M}+\mathrm{H}]^{+}$with 152 and $\mathrm{MS}^{2}$ of main peak m/z 226 gave three main fragment at m/z 152, 135 and 88. Among three fragments, m/z 152 was further bombarded and obtained $\mathrm{m} / \mathrm{z} 135$ and 88. On the other hand, in CID scan, acyclovir gave $\mathrm{m} / \mathrm{z}=226[\mathrm{M}+\mathrm{H}]^{+}$only. Which was further bombarded for $\mathrm{MS}^{2}$ and obtained m/z 152 and 135 only. MS3 of m/z 152 gave only one fragment from SID at $\mathrm{m} / \mathrm{z}$ 135.As shown in Table 1 and depicted in
Scheme 4, SID scan of penciclovir gave m/z $254[\mathrm{M}+\mathrm{H}]^{+}$with 152 and $\mathrm{MS}^{2}$ of main peak $\mathrm{m} / \mathrm{z} 254$ gave three main fragment at $\mathrm{m} / \mathrm{z}$ 152, 135 and 110. Among three fragments, m/z 152 was further bombarded and obtained m/z 135 and 110. On the other hand, in CID scan, penciclovir gave $\mathrm{m} / \mathrm{z}=254[\mathrm{M}+\mathrm{H}]^{+}$only. Which was further bombarded for $\mathrm{MS}^{2}$ and obtained m/z 152 only. $\mathrm{MS}^{3}$ of $\mathrm{m} / \mathrm{z}$ 152 gave same fragments as we obtained from SID, which is $\mathrm{m} / \mathrm{z}$ 135 and 110. As shown in Table 1 and depicted in Scheme 5, SID and CID scan of famciclovir gave only protonated peak at $\mathrm{m} / \mathrm{z} 322$ $[\mathrm{M}+\mathrm{H}]^{+}$. MS ${ }^{2}$ of this $\mathrm{m} / \mathrm{z} 322$ also gave four same fragments at $\mathrm{m} / \mathrm{z}$ 280, 262, 202 and 135. Among those peaks, a main peak m/z 280 was further bombarded and obtained seven fragments $\mathrm{m} / \mathrm{z} 262$, 238, 202, 186, 136, 117 and 107 in SID and 5 fragments m/z 262, 238, 202, 186 and 136 in CID. Common fragmentation paths of abacavir, acyclovir, penciclovir and famciclovir. 


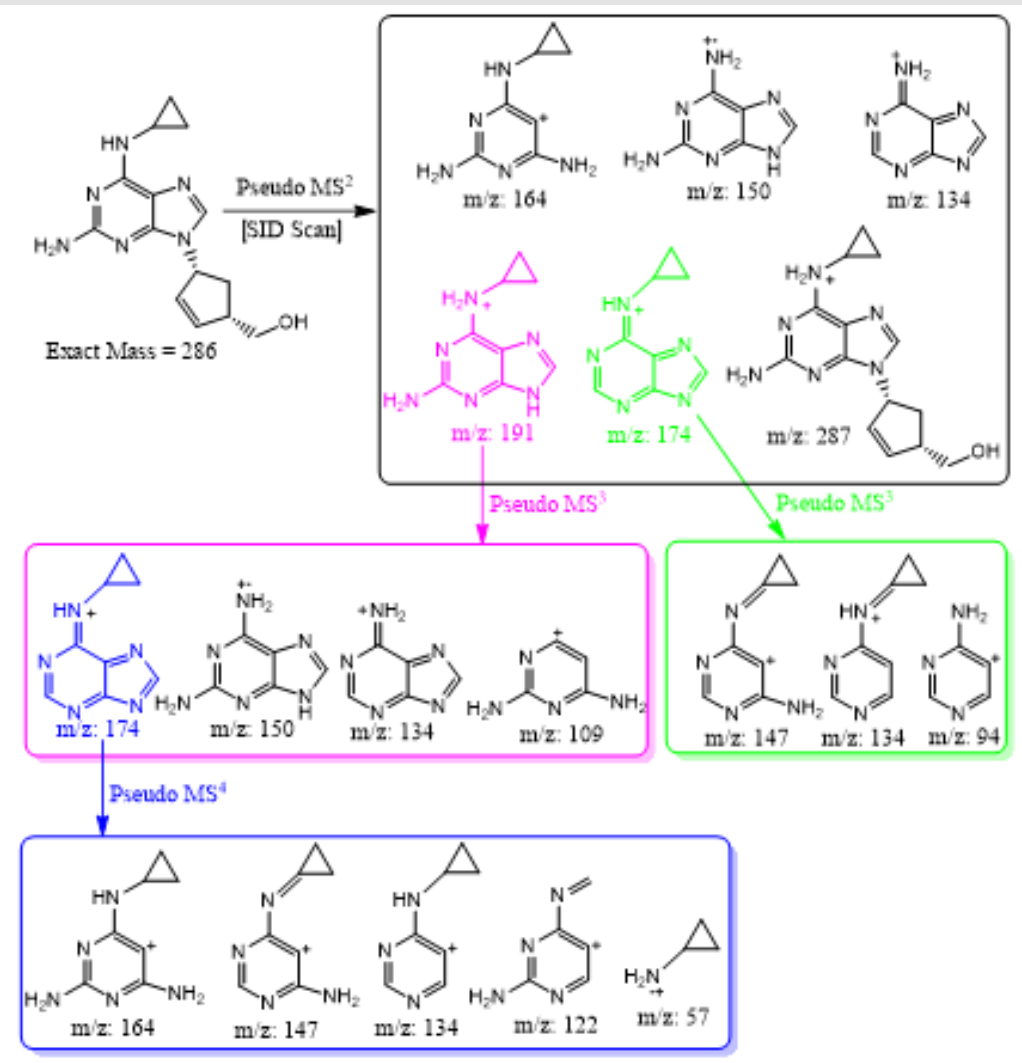

Scheme 2: In source fragmentation pattern of protonated abacavir.

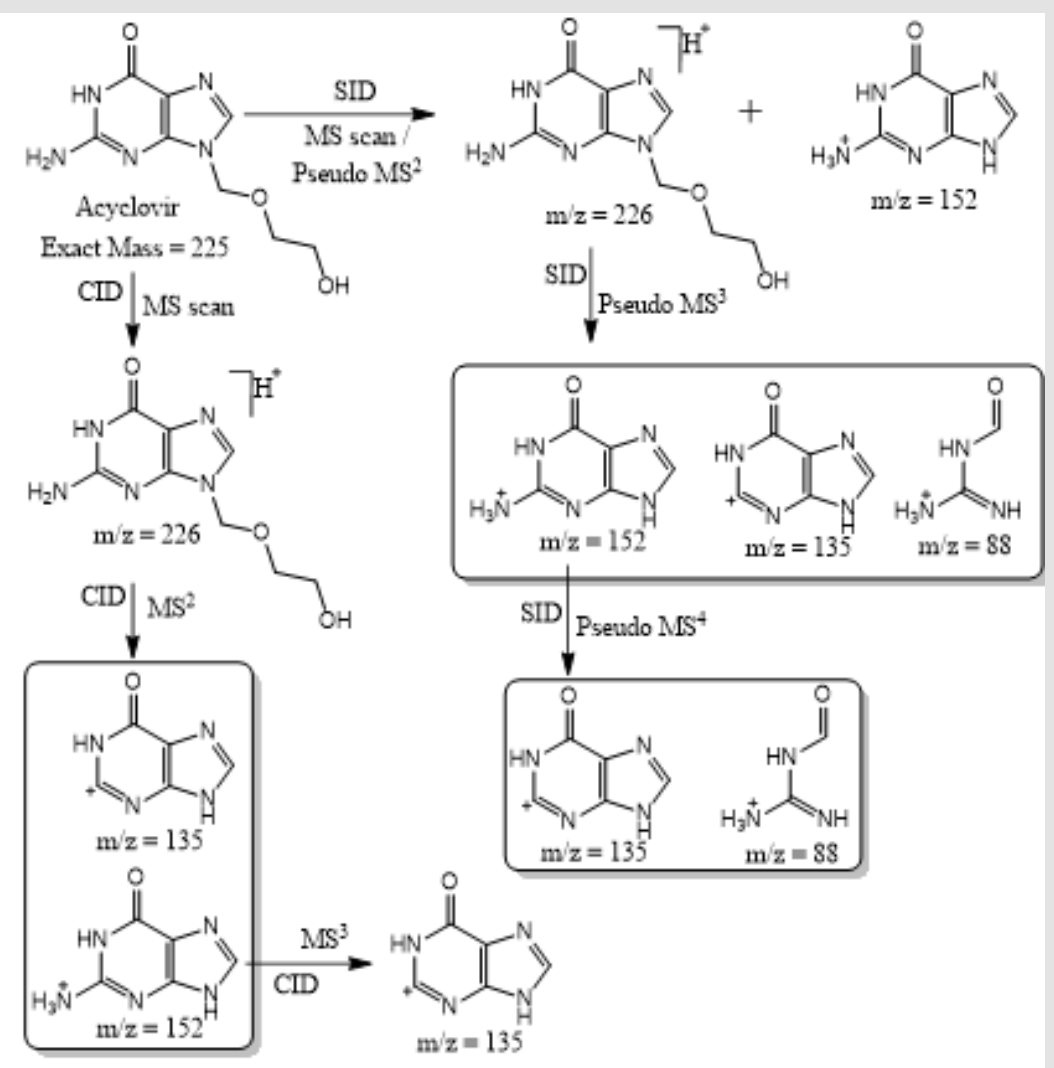

Scheme 3: Fragmentation pattern of acyclovir. 


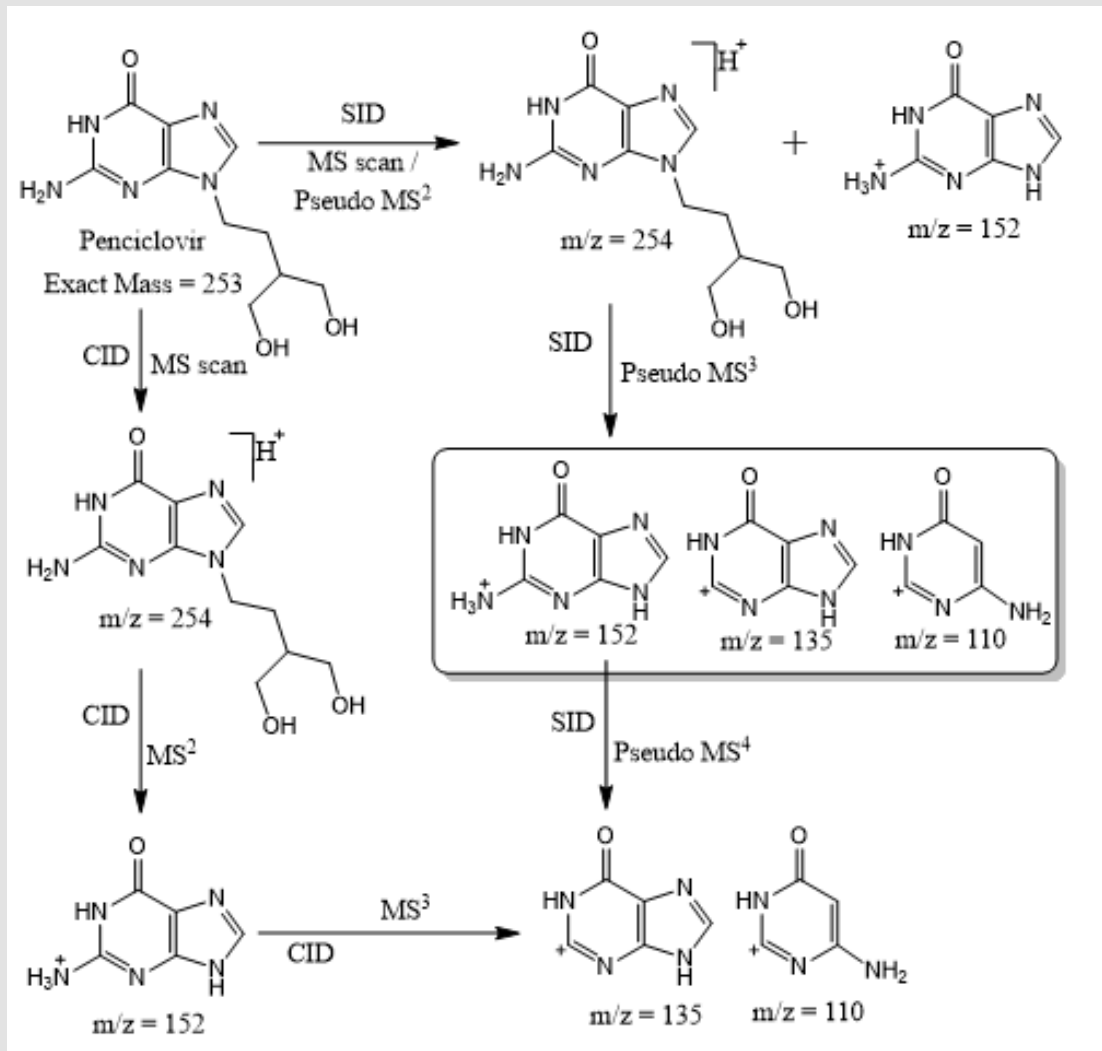

Scheme 4: Fragmentation pattern of penciclovir.

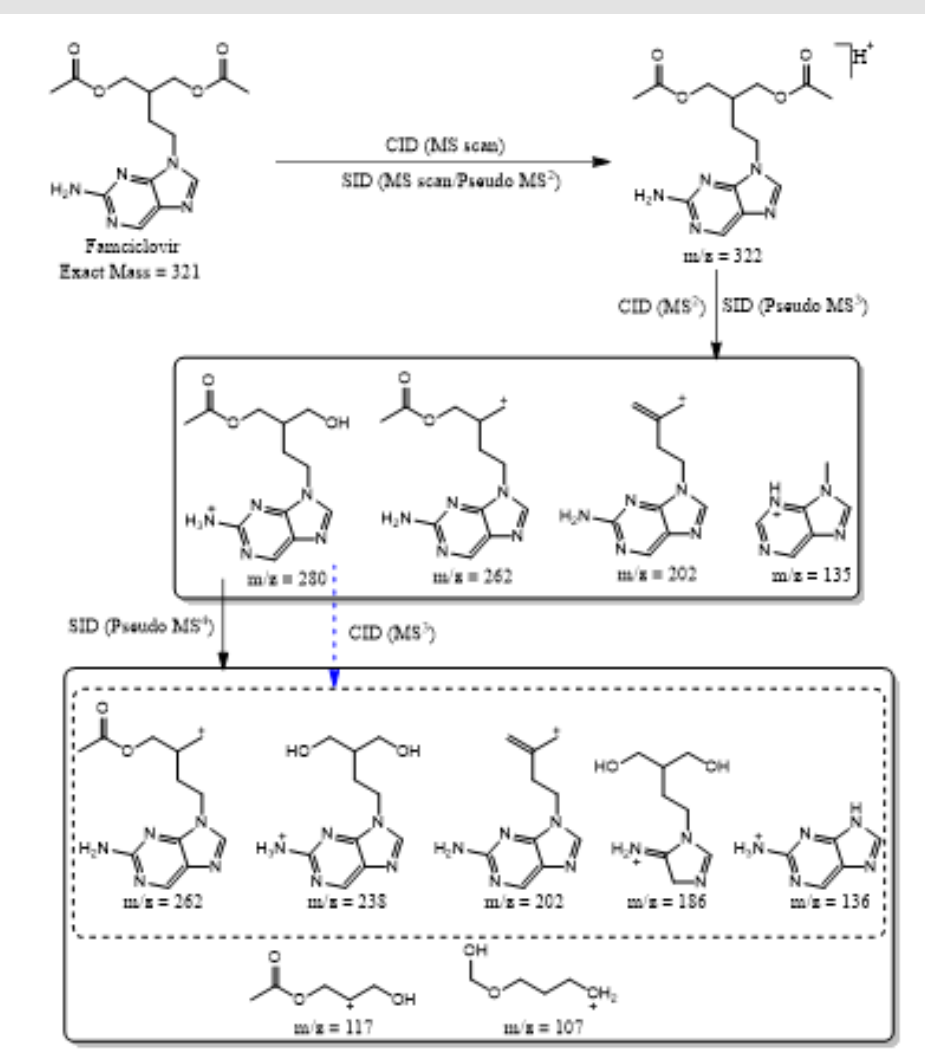

Scheme 5: Fragmentation pattern of famciclovir. 


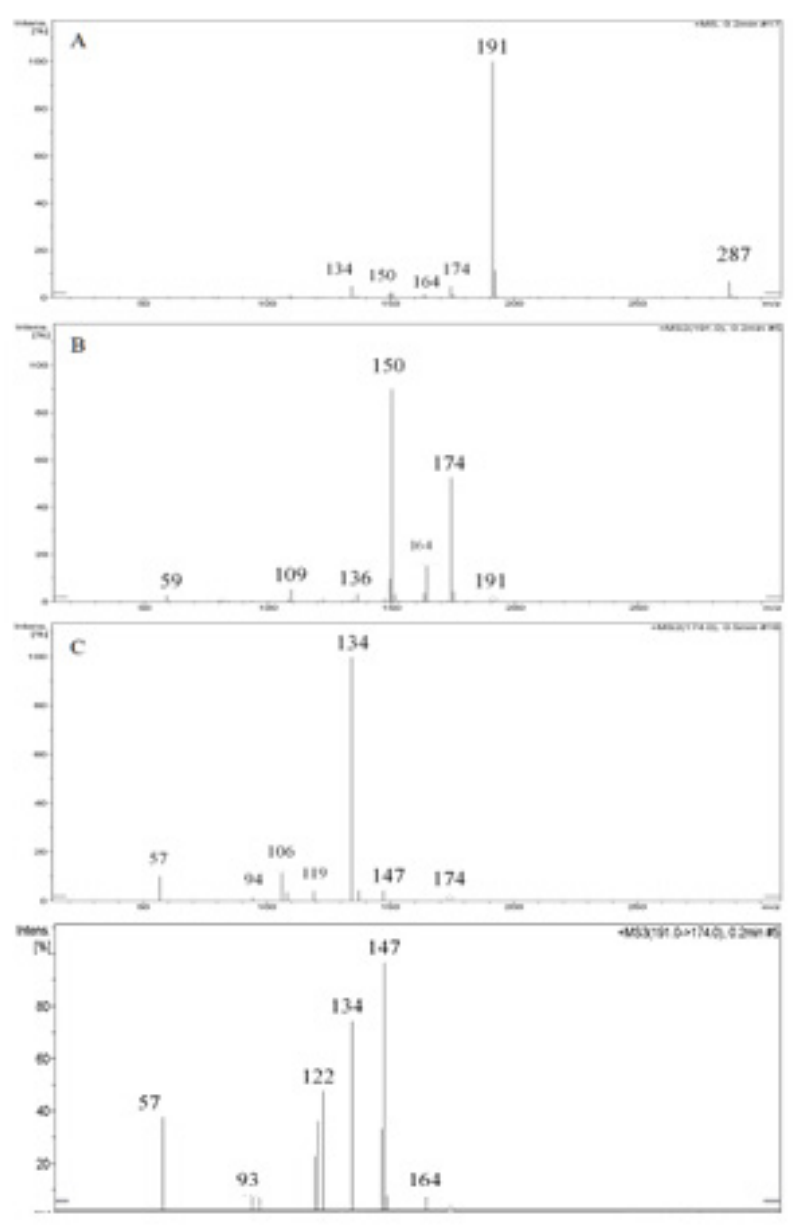

Figure 4: SID pseudo-MSn fragmentation pattern of abacavir:

A. MS scan for abacavir applying capillary exit voltage,

B. product ion for 191

C. product ion for 174 and

D. $\mathrm{MS}^{3}$ for 174 .

Table 1: MSn fragmentation behavior of acyclovir, penciclovir, famciclovir and abacavir.

\begin{tabular}{|c|c|c|c|c|c|c|}
\hline & $\begin{array}{c}\text { SID } \\
\text { (Scan/Pseudo } \\
\text { MS }^{2} \text { ) }\end{array}$ & $\begin{array}{c}\text { CID } \\
\text { (Scan) }\end{array}$ & $\begin{array}{c}\text { SID } \\
{\text { (Pseudo } \mathrm{MS}^{3} \text { ) }}^{\text {Pout }}\end{array}$ & $\begin{array}{l}\text { CID } \\
\left(M^{2}\right)\end{array}$ & $\begin{array}{c}\text { SID } \\
\text { (Pseudo MS }{ }^{4} \text { ) }\end{array}$ & $\begin{array}{l}\text { CID } \\
\left(\text { MS }^{3}\right)\end{array}$ \\
\hline Acyclovir & 226,152 & 226 & $\begin{array}{c}-226 \\
152,135,88\end{array}$ & (226) 152, 135 & $\begin{array}{c}-152 \\
135,88\end{array}$ & $\begin{array}{c}-152 \\
135\end{array}$ \\
\hline Penciclovir & 254,152 & 254 & $\begin{array}{c}-254 \\
152,135,110\end{array}$ & (254) 152 & (152) 135,110 & (152) 135,110 \\
\hline Famciclovir & 322 & 322 & $\begin{array}{c}-322 \\
280,262,202,135\end{array}$ & $\begin{array}{c}(322) 280,262 \\
202,135\end{array}$ & $\begin{array}{c}\text { (280) } 262,238,202,186 \\
136,117,107\end{array}$ & $\begin{array}{c}(280) 262,238 \\
202,186,136\end{array}$ \\
\hline Abacavir & $\begin{array}{l}287,191,174 \\
164,150,134\end{array}$ & 287 & $\begin{array}{c}-191 \\
174,164,150,136 \\
109,59 \\
-174 \\
147,134,119,106 \\
94,57\end{array}$ & $\begin{array}{c}-287 \\
257,191,150\end{array}$ & $\begin{array}{c}-174 \\
164,147,134,122,93 \\
57\end{array}$ & $\begin{array}{c}-191 \\
174,164,150,134 \\
109,83,59\end{array}$ \\
\hline
\end{tabular}

As depicted in Scheme 6, all four antiviral drugs gave similar fragmentation pathway. Abacavir, acyclovir and penciclovir gave purine moiety while SID / CID MS² was applied, on the other hand, famciclovir gave similar pathway with purine moiety while SID (Pseudo MS ${ }^{4}$ ) / CID $\left(\mathrm{MS}^{3}\right.$ ) was applied (Scheme 6). 


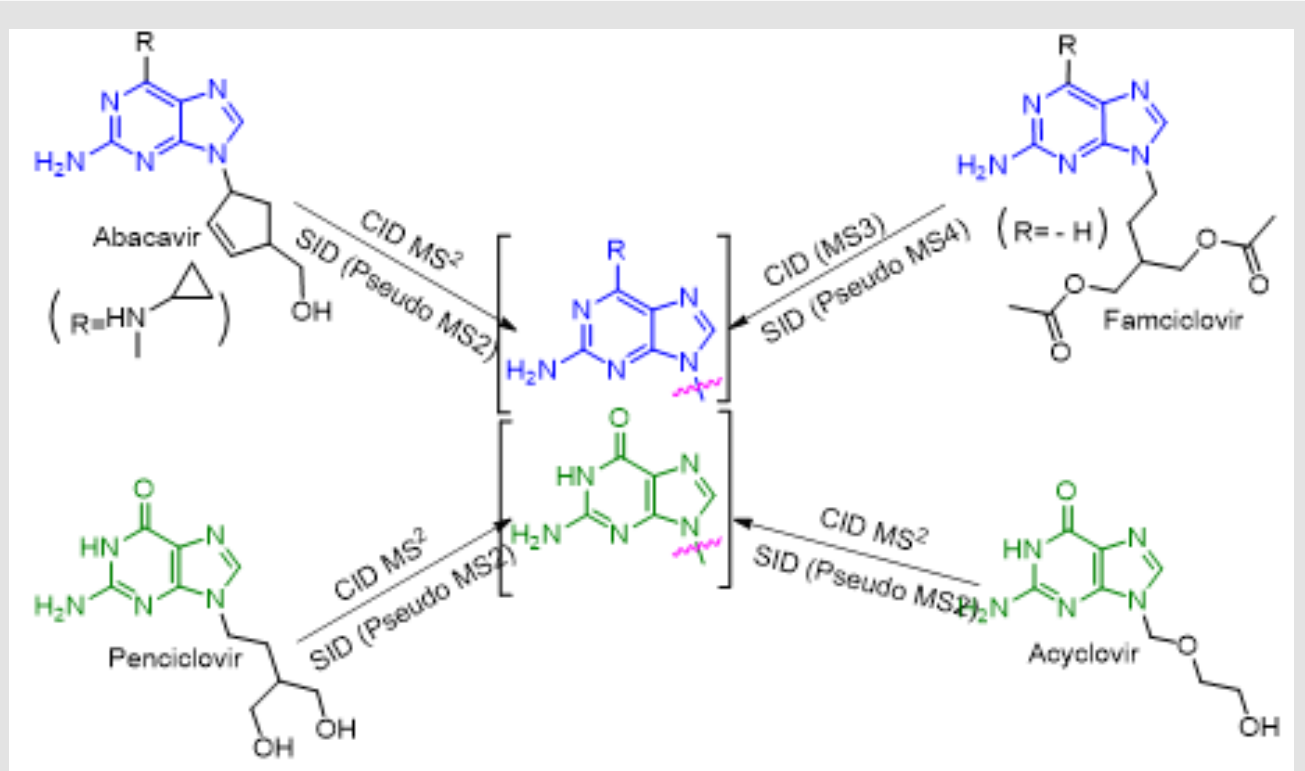

Scheme 6: Fragmentation pathways of all antiviral drugs (abacavir, acyclovir, penciclovir and famciclovir).

\section{Conclusion}

Excellent qualitative information was obtained using sourceinduced dissociation (SID) comparing to collision-induced dissociation (CID) in an ITMS. Fragmentation pathways of four antiviral drugs abacavir, acyclovir, penciclovir and famciclovir gave similar information regardless fragmentation method as they contain purine nucleus in their building blocks. This method can be applied for the detection /identification of know/unknown drugs or their metabolites in-vitro / in-vivo or in biological matrixes by comparing their fragmentation pattern and using different possible fragmentation tools to maximize the benefit of ITMS in the process of drug development.

\section{Declaration of Conflicting Interests}

The authors declared no conflicts of interest.

\section{Acknowledgements}

The authors would like to extend their sincere appreciation to the Deanship of Scientific Research at the King Saud University for funding this work through Research Group Project No. RG-1437033.

\section{References}

1. I A Kaltashov, C E Bobst, R R Abzalimo (2013) Mass spectrometry-based methods to study protein architecture and dynamics. Protein Science 22(5): 530-544.

2. M T Krahmer, Y A Johnson, J J Walters, K F Fox, A Fox, et al. (1999) Analytical Chemistry 71: 2893-2900.

3. A Kapur J L Beck, M M Sheil (1999) Observation of daunomycin and nogalamycin complexes with duplex DNA using electrospray ionisation mass spectrometry. Rapid Communications in Mass Spectrometry 13(24): 2489-2497.
4. G Lhoëst, T Zey, RK Verbeeck, P Wallemacq, N Maton, et al. (1999) Journal of mass spectrometry 34: 28-32.

5. W Mo, H Sakamoto, A Nishikawa, N Kagi, J I Langridge, et al. (1999) Structural Characterization of Chemically Derivatized Oligosaccharides by Nanoflow Electrospray Ionization Mass Spectrometry. Analytical chemistry 71(18): 4100-4106.

6. A Risberg, H Masoud, A Martin, J C Richards, E R Moxon, et al. (1999) Structural analysis of the lipopolysaccharide oligosaccharide epitopes expressed by a capsule-deficient strain of Haemophilus influenzae Rd. European journal of biochemistry 261(1): 171-180.

7. M Castillo, M C Alonso, J Riu, D Barceló (1999) Environmental science \& technology 33: 1300-1306.

8. M L Magnuson, E T Urbansky, C A Kelty (2000) Analytical Chemistry 72: 25-29.

9. N Kawasaki, M Ohta, S Hyuga, O Hashimoto, T Hayakawa, et al. (1999) Analysis of carbohydrate heterogeneity in a glycoprotein using liquid chromatography/mass spectrometry and liquid chromatography with tandem mass spectrometry. Analytical biochemistry 269(2): 297-303.

10. P Mauri, B Migliazza, P Pietta (1999) Liquid chromatography/ electrospray mass spectrometry of bioactive terpenoids in Ginkgo biloba L. Journal of mass spectrometry 34(12): 1361-1367.

11. M W Attwa, A A Kadi, A S Abdelhameed (2020) Detection and characterization of olmutinib reactive metabolites by LC-MS/MS: Elucidation of bioactivation pathways. Journal of Separation Science 43(4): 708-718.

12. Mohamed W Attwa, A A Kadi, H W Darwish, A S Abdelhameed (2018) nvestigation of the metabolic stability of olmutinib by validated LC-MS/ MS: quantification in human plasma. RSC Advances 8: 40387-40394.

13. A A Kadi, R F Angawi, M W Attwa, H W Darwish, A S Abdelhameed, et al. (2013) High Throughput Quantitative Bioanalytical LC/MS/MS Determination of Gemifloxacin in Human Urine. Journal of Chemistry 2013: 905704.

14. A A Kadi, A S Abdelhameed, H W Darwish, M W Attwa, A H Bakheit, et al. (2016) Liquid chromatographic-tandem mass spectrometric assay for simultaneous quantitation of tofacitinib, cabozantinib and afatinib in human plasma and urine. Tropical Journal of Pharmaceutical Research 15: 2683-2692. 
15. M W Attwa, A A Kadi, A S Abdelhameed, H A Alhazmi (2020) Metabolic Stability Assessment of New PARP Inhibitor Talazoparib Using Validated LC-MS/MS Methodology: In silico Metabolic Vulnerability and Toxicity Studies. Drug Des Devel Ther 14: 783-793.

16. A Putschew, M Jekel (2003) Induced in-source fragmentation for the selective detection of organic bound iodine by liquid chromatography/ electrospray mass spectrometry. Rapid Communications in Mass Spectrometry 17: 2279-2282.

17. A Hütteroth, A Putschew, M Jekel (2007) Selective detection of unknown organic bromine compounds and quantification potentiality by negativeion electrospray ionization mass spectrometry with induced in-source fragmentation. International Journal of Environmental and Analytical Chemistry 87(6): 415-424.

18. J H Gil, J K Hong, J C Choe, Y H Kim (2003) Analysis of Fatty Acyl Groups of Diacyl Galactolipid Molecular Species by HPLC/ESI-MS with In-source Fragmentation. Bulletin of the Korean Chemical Society 24(8): 11631168.

19. Q Tian, C J Duncan, S J Schwartz (2003) Structural characterization and isomer differentiation of chalcones by electrospray ionization tandem mass spectrometry. Journal of mass spectrometry 38(5): 990-995.

20. D J Carrier, C Eckers, J C Wolff (2008) In-source" fragmentation of an isobaric impurity of lamotrigine for its measurement by liquid chromatography tandem mass spectrometry after pre-concentration using solid phase extraction. Journal of pharmaceutical and biomedical analysis 47(4-5): 731-737

21. Z Yan, G W Caldwell, W J Jones, J A Masucci (2003) Cone voltage induced in-source dissociation of glucuronides in electrospray and implications in biological analyses. Rapid communications in mass spectrometry 17(13): 1433-1442.

22. G J Van Berkel, S A McLuckey, G L Glish (1991) Electrospray ionization of porphyrins using a quadrupole ion trap for mass analysis. Analytical Chemistry 63(11): 1098-1109.

23. A S Abdelhameed, A A Kadi, H A Abdel-Aziz, R F Angawi, M W Attwa, et al. (2014) Multistage Fragmentation of Ion Trap Mass Spectrometry System and Pseudo-MS ${ }^{3}$ of Triple Quadrupole Mass Spectrometry Characterize Certain (E)-3-(Dimethylamino)-1-arylprop-2-en-1-ones: A Comparative Study. The Scientific World Journal 2014: 702819.

\section{ISSN: 2574-1241}

DOI: 10.26717/BJSTR.2021.38.006218

A F M Motiur Rahman. Biomed J Sci \& Tech Res

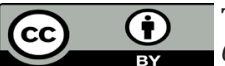

This work is licensed under Creative Commons Attribution 4.0 License

Submission Link: https://biomedres.us/submit-manuscript.php
24. A S Abdelhameed, A A Kadi, M I Attia, R F Angawi, M W Attwa, et al. (2014) seudo-MS ${ }^{3}$ Approach Using Electrospray Mass Spectrometry (ESI-MS/MS) to Characterize Certain (2E)-2-[3-(1H-Imidazol-1-yl)1-phenylpropylidene]hydrazinecarboxamide Derivatives. Journal of Chemistry 2014: 386301

25. A S Abdelhameed, M W Attwa, H A Abdel-Aziz, A A Kadi (2013) Induced in-source fragmentation pattern of certain novel $(1 \mathrm{Z}, 2 \mathrm{E})-\mathrm{N}-(\operatorname{aryl})$ propanehydrazonoyl chlorides by electrospray mass spectrometry (ESIMS/MS). Chemistry Central Journal 7(1): 16.

26. E De Clerq, H J Field (2006) Antiviral prodrugs - the development of successful prodrug strategies for antiviral chemotherapy. Br J Pharmacol 147(1): 1-11.

27. P I Rafailidis, M N Mavros, A Kapaskelis, M E Falagas (2010) Antiviral treatment for severe EBV infections in apparently immunocompetent patients. Journal of clinical virology 49(3): 151-157.

28. S Mallal, D Nolan, C Witt, G Masel, A Martin, C Moore, D Sayer, et al (2002) Association between presence of HLA-B ${ }^{*} 5701$, HLA-DR7, and HLA-DQ3 and hypersensitivity to HIV-1 reverse-transcriptase inhibitor abacavir. The Lancet 359(9308): 727-732.

29. G J Yuen, S Weller, G E Pakes (2008) A review of the pharmacokinetics of abacavir. Clinical pharmacokinetics 47(6): 351-371.

30.S Tyring, R A Barbarash J E, Nahlik, A Cunningham, J Marley M, et al. (1995) Annals of Internal Medicine, 123: 89-96.

31. A D Luber, JF Flaherty Jr (1996) Famciclovir for Treatment of Herpesvirus Infections. Annals of Pharmacotherapy 30(9): 978-985.

32. E M Alapi, J Fischer (2006) Analogue-based drug discovery. Wiley-VCH, Weinheim 441-552.

33. S L Spruance, N Bodsworth, H Resnick, M Conant, C Oeuvray, et al. (2006) The burden of skin diseases: 2004 a joint project of the American Academy of Dermatology Association and the Society for Investigative Dermatology. Journal of the American Academy of Dermatology 55(3): 47-53.

34. H Rosemeyer (2004) The Chemodiversity of Purine as a Constituent of Natural Products. Chemistry \& biodiversity 1(3): 361-401.

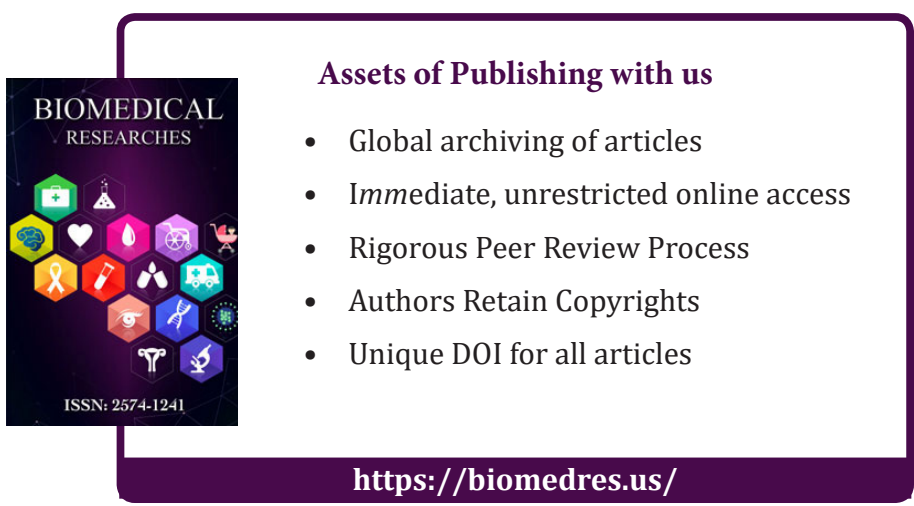

